\title{
SPECTRUL FAUNISTIC AL NOCTUIDELOR SEMNALATE ÎN COMUNA BRÎNZENI (EDINET) ÎN PERIOADA ANILOR 2012-2016
}

\author{
Țugulea Cristina \\ Institutul de Zoologie, Chișinău, Republica Moldova, \\ tuguleacristy@yahoo.com \\ https://doi.org/10.53937/9789975315975.65
}

\begin{abstract}
In the years 2012-2016 the moths of the Noctuidae family were systematically collected in Brînzeni (Edinet). 3232 specimens of moths were collected in traps with white and ultraviolet light. Following investigations, were identified 124 species of moths belong to 71 genres and 11 subfamilies. Three genres and 8 species are new to the fauna of the Republic of Moldova.
\end{abstract}

Key words: Noctuidae, Brînzeni, species.

\section{INTRODUCERE}

Efectuarea unui studiu sistematic asupra acestui grup de insecte ne permite să completăm baza de date informațională a Republicii Moldova și a Europei și să conturăm un tablou clar asupra stării și spectrului faunistic al acestei familii de fluturi din diferite ecosisteme naturale și antropizate, care lipsește la momentul actual. Lipsa lucrărilor științifice și studierii ineficiente a noctuidelor îngreunează analiza detaliată și nu oferă o imagine completă a biodiversităţii faunei regionale.

Familia Noctuidae este una dintre cele mai mari familii din ordinul Lepidoptera. Conform ultimului studiu în Republica Moldova sunt înregistrate aproximativ 410 specii [4] pe când în fauna europeană sunt citate aproximativ 1450 de specii [1]. În ultimii ani, un șir de factori au dus la scăderea efectivului numeric al populațiilor multor specii de noctuide. În timp ce multe specii nu s-au mai colectat de câteva decenii, altele noi își fac apariția în fauna țării noastre. De asemenea este importantă monitorizarea efectivului numeric al populațiilor speciilor care pot provoca 
daune culturilor agricole. Investigațiile asupra ecosistemelor naturale și antropizate din apropierea c. Brînzeni au început din 2012 și continuă pănă în prezent.

\section{MATERIALE ȘI METODE DE CERCETARE}

Pe parcursul anilor 2012-2016 s-au efectuat colectări sistematice în c. Brânzeni (raionul Edineț) la stațiunea Institutului de Zoologie (responsabil dl dr. I. Chiriac). Materialul entomologic a fost colectat la capcane entomologice cu lumină albă și ultravioletă. Capcana cu lumină asigură colectarea lepidopterelor nocturne, pe o suprafaţă extinsă. Ca metodă de capturare este relevantă pentru studii calitative (taxonomice, faunistice, zoogeografice) și cantitative (abundenţa, frecvenţa și fenologia speciei, dinamica populaţiei). Materialul colectat a fost etichetat și determinat după cele mai recent publicate chei și lucrări taxonomice.

\section{REZULTATE ȘI DISCUȚII}

În urma investigațiilor au fost colectate și determinate 3232 de exemplare de noctuide. Din datele expuse în tabelul de mai jos se poate observa că numărul de lepidoptere colectate la cele două surse de lumină (albă și ultravioletă) diferă. La capcana cu lumină albă s-au colectat 1054 de exemplare, iar la cea ultravioletă - 2178 de exemplare. Majoritatea indivizilor au preferat ambele surse de lumină (speciile cu o densitate mai mare a populațiilor), dând totuși preferință capcanei cu lumină ultravioletă. Un număr mic de specii, cum ar fi Eucarta virgo Treist. (specie noua pentru fauna Republicii Moldova), care a preferat sursa de lumină albă.

În urma sistematizării materialului colectat au fost identificate 124 de specii de noctuide. Cele mai multe specii aparțin subfamiliei Noctuinae (95 specii), iar subfamiliile Metoponiinae și Oncocnemidinae înregistrează o singură specie (fig. 1). Spectrul faunistic al noctuidelor colectate este prezentat în Tabelul 1. Fiecare specie este însoțită de date privind perioada colectării și numărul de exemplare. 


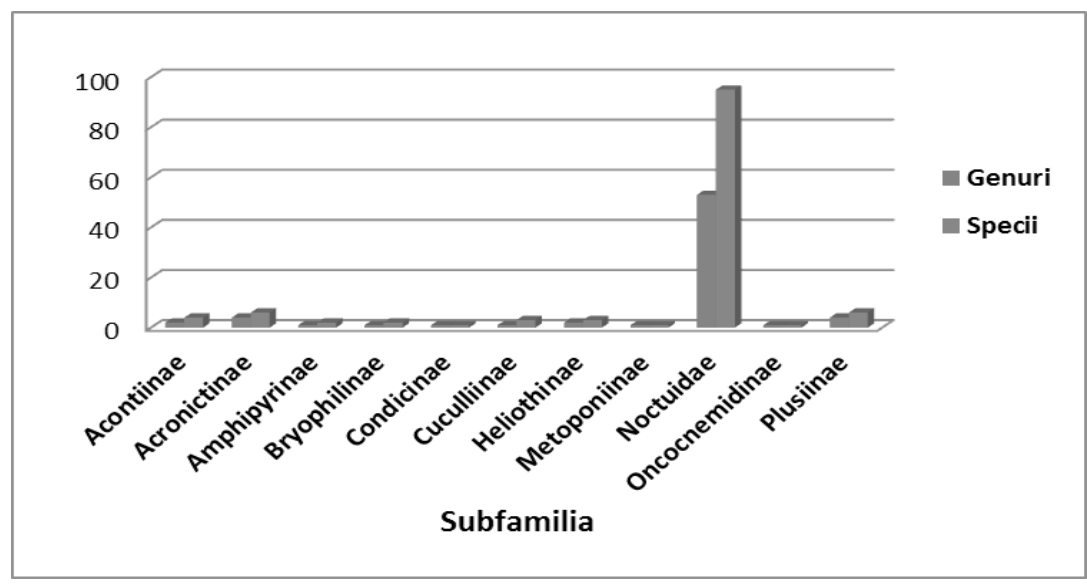

Figura 1. Structura taxonomică a lepidopterelor din familia Noctuidae colectate în c. Brînzeni.

Fluctuaţiile climatice și schimbarea structurii biocenotice influenţează direct efectivul numeric și densitatea populațiilor de fluturi. Frecvența speciilor demonstrează sensibilitatea acestora la condițiile mediului. Observăm cât de accentuat este raportul între speciile cu o frecvență foarte rară (58 de specii ) și doar 4 specii (Acontia trabealis Scop., Anarta trifolii Hufn., Agrotis exclamationis L., Xestia c-nigrum L.), care se întâlnesc foarte frecvent colectându-se la capcanele cu lumină mai mult de 16 exemplare pe zi [2].

În urma investigațiilor au fost identificate 8 specii noi pentru fauna țării, taxonomic încadrate în 3 subfamilii: Noctuinae, Acontiinae și Condicinae. Lista faunistică a speciilor noi colectate în c. Brînzeni, însoțită de locul și data colectări a fost expusă în lucrarea precedentă [3]. Mai jos sunt citate speciile care completează lista existentă: subfamilia Noctuinae - Hadena capsincola Schiff., 24.06.16 - 2 ex., Abrostola asclepiadis Schiff., 18.07.14 - 1 ex. și subfamilia Condicinae: Eucarta virgo Treist., 17.07.12 - 2 ex., 19.07.12 - 1 ex. 
Tabelul 1. Spectrul faunistic al noctuidelor semnalate în c. Brînzeni (Edineț) în perioada anilor 2012-2016

\begin{tabular}{|c|c|c|c|c|c|c|c|c|c|c|c|c|c|c|c|c|c|}
\hline \multirow{3}{*}{ Nr. } & \multirow{3}{*}{ Specia } & \multicolumn{15}{|c|}{ Materialul colectat (anii și sursa de lumină) } & \multirow{3}{*}{$\begin{array}{l}\text { To- } \\
\text { tal }\end{array}$} \\
\hline & & \multicolumn{3}{|c|}{2012} & \multicolumn{3}{|c|}{2013} & \multicolumn{3}{|c|}{2014} & \multicolumn{3}{|c|}{2015} & \multicolumn{3}{|c|}{2016} & \\
\hline & & $\mathrm{T}$ & UV & A & $T$ & UV & A & $\mathrm{T}$ & UV & A & $\mathrm{T}$ & UV & A & $\mathrm{T}$ & UV & A & \\
\hline \multicolumn{18}{|c|}{ Subfamilia ACONTIINAE } \\
\hline 1 & $\frac{\text { Acontia lucida }}{\text { (Hufnagel, 1766) }}$ & 11 & 7 & 4 & 7 & 4 & 3 & 2 & 1 & 1 & 2 & 1 & 1 & 4 & 3 & 1 & 26 \\
\hline 2 & $\begin{array}{l}\text { *A. candefacta } \\
\text { (Hübner, 1831) }\end{array}$ & - & - & - & - & - & - & - & - & - & 1 & - & 1 & 7 & 6 & 1 & 8 \\
\hline 3 & $\begin{array}{l}\text { A. trabealis (Sco- } \\
\text { poli, 1763) }\end{array}$ & 126 & 115 & 11 & 98 & 73 & 25 & 45 & 28 & 17 & 56 & 36 & 20 & 215 & 169 & 46 & 540 \\
\hline 4 & $\frac{\text { Aedia funesta }}{\text { (Esper, 1786) }}$ & 1 & 1 & - & 5 & 3 & 2 & 5 & 3 & 2 & 1 & - & 1 & 1 & 1 & - & 13 \\
\hline \multicolumn{18}{|c|}{ Subfamilia ACRONICTINAE } \\
\hline 5 & $\begin{array}{l}\text { Acronicta tridens } \\
\text { (Denis \& Schiffer- } \\
\text { müller, 1775) } \\
\end{array}$ & - & - & - & - & - & - & - & - & - & - & - & - & 1 & 1 & - & 1 \\
\hline 6 & $\begin{array}{l}\text { A. cuspis (Hübner, } \\
1813 \text { ) }\end{array}$ & - & - & - & - & - & - & 1 & - & 1 & - & - & - & - & - & - & 1 \\
\hline 7 & $\begin{array}{l}\text { A. rumicis (Lin- } \\
\text { naeus, 1758) }\end{array}$ & 6 & 6 & - & 2 & 1 & 1 & 6 & 3 & 3 & 5 & 2 & 3 & 2 & - & 2 & 21 \\
\hline 8 & $\begin{array}{l}\text { Craniophora } \\
\text { ligustri (Denis \& } \\
\text { Schiffermüller, } \\
\text { 1775) } \\
\end{array}$ & - & - & - & - & - & - & 3 & 3 & - & - & - & - & - & - & - & 3 \\
\hline 9 & $\begin{array}{l}\text { Oxicesta geogra- } \\
\text { phica (Fabricius, } \\
\text { 1787) } \\
\end{array}$ & - & - & - & - & - & - & - & - & - & - & - & - & 1 & - & 1 & 1 \\
\hline 10 & $\begin{array}{l}\text { Subacronicta me- } \\
\text { gacephala (Denis } \\
\& \text { Schiffermüller, } \\
1775 \text { ) }\end{array}$ & 1 & 1 & - & - & - & - & - & - & - & - & - & - & - & - & - & 1 \\
\hline \multicolumn{18}{|c|}{ Subfamilia AMPHIPYRINAE } \\
\hline 11 & $\begin{array}{l}\text { Amphipyra livida } \\
\text { (Denis \& Schiffer- } \\
\text { müller, 1775) }\end{array}$ & - & - & - & 2 & - & 2 & - & - & - & - & - & - & - & - & - & 2 \\
\hline 12 & $\begin{array}{l}\text { A. tragopogi- } \\
\text { nis (Clerck, 1759) }\end{array}$ & - & - & - & 1 & 1 & - & - & - & - & - & - & - & - & - & - & 1 \\
\hline \multicolumn{18}{|c|}{ Subfamilia BRYOPHILINAE } \\
\hline 13 & $\begin{array}{l}\text { Cryphia fraudatri- } \\
\text { cula (Hübner, } \\
\text { 1803) }\end{array}$ & - & - & - & 1 & - & 1 & - & - & - & - & - & - & 3 & 3 & - & 4 \\
\hline 14 & $\begin{array}{l}\text { C. algae (Fabri- } \\
\text { cius, 1775) }\end{array}$ & - & - & - & - & - & - & 4 & 4 & - & - & - & - & 1 & - & 1 & 5 \\
\hline \multicolumn{18}{|c|}{ Subfamilia CONDICINAE } \\
\hline 15 & $\begin{array}{l}\text { Eucarta virgo (Tre- } \\
\text { itschke, 1835) }\end{array}$ & 3 & - & 3 & - & - & - & - & - & - & - & - & - & - & - & - & 3 \\
\hline \multicolumn{18}{|c|}{ Subfamilia CUCULLIINAE } \\
\hline 16 & $\begin{array}{l}\text { Cucullia frau- } \\
\text { datrix Eversmann, } \\
1837\end{array}$ & 1 & 1 & - & 1 & - & 1 & - & - & - & 1 & - & 1 & - & - & - & 3 \\
\hline
\end{tabular}




\begin{tabular}{|c|c|c|c|c|c|c|c|c|c|c|c|c|c|c|c|c|c|}
\hline 17 & $\begin{array}{l}\text { C. lactucae (Denis } \\
\text { \& Schiffermüller, } \\
1775 \text { ) }\end{array}$ & - & - & - & - & - & - & 1 & 1 & - & - & - & - & - & & - & 1 \\
\hline 18 & $\begin{array}{l}\text { C. lucifuga (Denis } \\
\text { \& Schiffermüller, } \\
1775 \text { ) }\end{array}$ & 1 & - & 1 & - & - & - & - & - & - & - & - & - & - & - & - & 1 \\
\hline \multicolumn{18}{|c|}{ Subfamilia HELIOTHINAE } \\
\hline 19 & $\begin{array}{l}\text { Helicoverpa ar- } \\
\text { migera (Hübner, } \\
\underline{1808)}\end{array}$ & 13 & 6 & 7 & 6 & 5 & 1 & 3 & 2 & 1 & 2 & 2 & - & 13 & 8 & 5 & 37 \\
\hline 20 & $\begin{array}{l}\text { H. maritima (Gras- } \\
\text { lin, 1855) }\end{array}$ & 2 & 1 & 1 & - & - & - & - & - & - & 1 & - & 1 & - & - & - & 3 \\
\hline 21 & $\begin{array}{l}\text { Protoschinia } \\
\text { scutosa (Denis } \\
\text { \& Schiffermüller, } \\
1775 \text { ) }\end{array}$ & 1 & - & 1 & - & - & - & - & - & - & 1 & - & 1 & 1 & 1 & - & 3 \\
\hline \multicolumn{18}{|c|}{ Subfamilia METOPONIINAE } \\
\hline 22 & $\begin{array}{l}\text { Tyta luctuosa } \\
\text { (Denis \& Schiffer- } \\
\text { müller, 1775) }\end{array}$ & 8 & 6 & 2 & 16 & 13 & 3 & 12 & 8 & 4 & 6 & 3 & 3 & 14 & 10 & 4 & 56 \\
\hline \multicolumn{18}{|c|}{ Subfamilia NOCTUINAE } \\
\hline 23 & \begin{tabular}{|l|} 
Actinotia polyo- \\
don (Clerck, 1759)
\end{tabular} & - & - & - & - & - & - & - & - & - & 1 & - & 1 & - & - & - & 1 \\
\hline 24 & \begin{tabular}{|l|} 
Amphipoea fuco- \\
sa (Freyer, 1830)
\end{tabular} & - & - & - & 1 & 1 & - & - & - & - & 1 & - & 1 & 2 & 2 & - & 4 \\
\hline 25 & $\begin{array}{l}\text { Apamea mono- } \\
\text { glypha (Hufnagel, } \\
\text { 1766) }\end{array}$ & - & - & - & - & - & - & - & - & - & - & - & - & 1 & 1 & - & 1 \\
\hline 26 & $\begin{array}{l}\text { A. sordens (Hufna- } \\
\text { gel, 1766) }\end{array}$ & 1 & 1 & - & 1 & 1 & - & 2 & 2 & - & 1 & - & 1 & 3 & 2 & 1 & 8 \\
\hline 27 & $\begin{array}{l}\text { Calamia tridens } \\
\text { (Hufnagel, 1766) }\end{array}$ & - & - & - & 1 & - & 1 & - & - & - & 2 & - & 2 & - & - & - & 3 \\
\hline 28 & $\begin{array}{l}\text { Lenisa gemini- } \\
\text { puncta (Haworth, } \\
1809 \text { ) }\end{array}$ & - & - & - & - & - & - & - & - & - & 1 & - & 1 & 1 & - & 1 & 2 \\
\hline 29 & $\begin{array}{l}\text { Luperina testacea } \\
\text { (Denis \& Schiffer- } \\
\text { müller, 1775) }\end{array}$ & 2 & - & 2 & 1 & - & 1 & 3 & 1 & 2 & - & - & - & 7 & 7 & - & 13 \\
\hline 30 & $\begin{array}{l}\text { Mesoligia furun- } \\
\text { cula (Denis \& } \\
\text { Schiffermüller, } \\
1775 \text { ) }\end{array}$ & - & - & - & - & - & - & 1 & - & 1 & - & - & - & 1 & 1 & - & 2 \\
\hline 31 & $\begin{array}{l}\text { Nonagria typhae } \\
\text { (Thunberg, 1784) }\end{array}$ & - & - & - & 1 & 1 & - & 1 & - & 1 & - & - & - & 1 & 1 & - & 3 \\
\hline 32 & $\begin{array}{l}\text { Oligia latruncu- } \\
\text { la (Denis \& Schi- } \\
\text { ffermüller, 1775) }\end{array}$ & - & - & - & 1 & - & 1 & - & - & - & 3 & - & 3 & - & - & - & 4 \\
\hline 33 & $\begin{array}{l}\text { O. strigilis (Lin- } \\
\text { naeus, 1758) }\end{array}$ & 2 & 1 & 1 & 1 & 1 & - & 2 & 2 & - & - & - & - & 7 & 4 & 3 & 12 \\
\hline
\end{tabular}




\begin{tabular}{|c|c|c|c|c|c|c|c|c|c|c|c|c|c|c|c|c|c|}
\hline 34 & $\begin{array}{l}\text { O. versicolor (Bor- } \\
\text { khausen, 1792) }\end{array}$ & - & & & & & & 4 & 2 & 2 & & - & - & 11 & 7 & 4 & 15 \\
\hline 35 & $\begin{array}{l}\text { Athetis furvula } \\
\text { (Hübner, 1808) }\end{array}$ & - & & & 5 & 4 & 1 & & & - & & - & - & 8 & 7 & 1 & 13 \\
\hline 36 & $\begin{array}{l}\text { A. gluteosa (Treit- } \\
\text { schke,1835) }\end{array}$ & & & & 1 & 1 & 0 & 9 & 6 & 3 & & & & 6 & 4 & 2 & 16 \\
\hline 37 & $\begin{array}{l}\text { Caradrina mor- } \\
\text { pheus (Hufnagel, } \\
\text { 1766) }\end{array}$ & 9 & 5 & 4 & 4 & 3 & 1 & 8 & 6 & 2 & 9 & 4 & 5 & 7 & 4 & 3 & 37 \\
\hline 38 & $\begin{array}{l}\text { C. clavipalpis } \\
\text { (Scopoli,1763) }\end{array}$ & 3 & 2 & 1 & 4 & 4 & 0 & 4 & 3 & 1 & - & - & - & 3 & 3 & 0 & 14 \\
\hline 39 & $\begin{array}{l}\text { C. kadenii Freyer, } \\
1836\end{array}$ & 2 & 1 & 1 & - & - & - & & - & - & - & - & - & - & - & - & 2 \\
\hline 40 & $\begin{array}{l}\text { Charanyca tri- } \\
\text { grammica (Hufna- } \\
\text { gel, 1766) }\end{array}$ & - & - & - & - & - & - & 1 & 1 & - & - & - & - & 4 & 4 & - & 5 \\
\hline 41 & $\begin{array}{l}\text { Chilodes maritima } \\
\text { (Tauscher, 1806) }\end{array}$ & - & - & - & - & - & - & - & - & - & - & - & - & 1 & 1 & - & 1 \\
\hline 42 & $\begin{array}{l}\text { Hoplodrina ambi- } \\
\text { gua (Denis \& Schi- } \\
\text { ffermüller, 1775) }\end{array}$ & 18 & 13 & 5 & 15 & 9 & 6 & 39 & 27 & 12 & 36 & 23 & 13 & 32 & 28 & 4 & 140 \\
\hline 43 & $\begin{array}{l}\text { H. blanda (Denis } \\
\begin{array}{l}\text { \& Schiffermüller, } \\
1775)\end{array}\end{array}$ & 5 & 5 & - & 1 & - & 1 & 1 & - & 1 & - & - & - & - & - & - & 7 \\
\hline 44 & $\begin{array}{l}\frac{\text { H. octogenaria }}{(\text { Goeze, 1781) }} \\
\end{array}$ & 3 & 3 & - & 2 & 2 & - & 3 & 2 & 1 & - & - & - & 30 & 25 & 5 & 38 \\
\hline 45 & $\begin{array}{l}\text { H. superstes (Och- } \\
\text { senheimer, 1816) }\end{array}$ & 7 & 6 & 1 & 1 & 1 & - & 2 & 1 & 1 & - & - & - & - & - & - & 10 \\
\hline 46 & $\begin{array}{l}\text { Dypterygia sca- } \\
\text { briuscula (Lin- } \\
\text { naeus, 1758) } \\
\end{array}$ & - & - & - & 1 & - & 1 & 1 & 1 & - & - & - & - & 4 & 1 & 3 & 6 \\
\hline 47 & $\begin{array}{l}\text { Thalpophila ma- } \\
\text { tura (Hufnagel, } \\
\text { 1766) }\end{array}$ & 2 & 2 & - & 2 & 2 & - & 6 & 4 & 2 & 6 & 6 & - & 7 & 5 & 2 & 23 \\
\hline 48 & $\begin{array}{l}\text { Trachea atriplicis } \\
\text { (Linnaeus, 1758) }\end{array}$ & & & & 3 & 2 & 1 & 3 & 0 & 3 & 1 & 0 & 1 & 4 & 3 & 1 & 11 \\
\hline 49 & $\begin{array}{l}\text { Episema glauci- } \\
\text { na (Esper, 1789) }\end{array}$ & 1 & & 1 & - & - & - & & - & - & - & - & - & - & - & - & 1 \\
\hline 50 & $\begin{array}{l}\text { Anarta trifolii (Huf- } \\
\text { nagel, 1766) }\end{array}$ & 30 & 21 & 9 & 19 & 10 & 9 & 6 & 3 & 3 & 40 & 21 & 19 & 187 & 140 & 47 & 282 \\
\hline 51 & $\begin{array}{l}\text { Conisania luteago } \\
\text { (Denis \& Schiffer- } \\
\text { müller, 1775) }\end{array}$ & - & - & - & - & - & - & 1 & - & 1 & 1 & - & 1 & 5 & 4 & 1 & 7 \\
\hline 52 & $\begin{array}{l}\text { Hada plebeja (Lin- } \\
\text { naeus, 1761) }\end{array}$ & 1 & 1 & - & 1 & 1 & - & 5 & 1 & 4 & 5 & 1 & 4 & 5 & 4 & 1 & 17 \\
\hline 53 & \begin{tabular}{|l|} 
*Hadena cap- \\
sincola (Denis \& \\
Schiffermüller, \\
1775 )
\end{tabular} & - & - & - & 1 & 1 & - & - & - & - & - & - & - & 12 & 3 & 9 & 13 \\
\hline
\end{tabular}




\begin{tabular}{|c|c|c|c|c|c|c|c|c|c|c|c|c|c|c|c|c|c|}
\hline 54 & $\begin{array}{l}\text { Hecatera bicolo- } \\
\text { rata (Hufnagel, } \\
1766)\end{array}$ & - & - & - & - & - & - & - & - & - & 1 & 1 & - & - & - & - & 1 \\
\hline 55 & $\begin{array}{l}\text { H. dysodea (Denis } \\
\text { \& Schiffermüller, } \\
1775 \text { ) }\end{array}$ & 3 & 1 & 2 & 2 & 1 & 1 & - & - & - & - & - & - & 3 & 2 & 1 & 8 \\
\hline 56 & $\begin{array}{l}\text { Lacanobia suasa } \\
\text { (Denis \& Schiffer- } \\
\text { müller, 1775) }\end{array}$ & 6 & 5 & 1 & - & - & - & 2 & - & 2 & 4 & 4 & - & 1 & 1 & - & 13 \\
\hline 57 & $\begin{array}{l}\text { L. thalassina (Huf- } \\
\text { nagel, 1766) }\end{array}$ & 8 & 6 & 2 & 6 & 4 & 2 & 5 & 3 & 2 & 4 & 2 & 2 & 14 & 13 & 1 & 37 \\
\hline 58 & $\begin{array}{l}\text { L. oleracea (Lin- } \\
\text { naeus, 1758) }\end{array}$ & 4 & 2 & 2 & 7 & 3 & 4 & 14 & 2 & 12 & 5 & 1 & 4 & 5 & 4 & 1 & 35 \\
\hline 59 & $\begin{array}{l}\text { L. w-latinum (Huf- } \\
\text { nagel, 1766) }\end{array}$ & - & - & - & - & - & - & 2 & - & 2 & - & - & - & 4 & 4 & - & 6 \\
\hline 60 & $\begin{array}{l}\text { L. splen- } \\
\text { dens (Hübner, } \\
1808 \text { ) }\end{array}$ & 1 & 1 & - & - & - & - & - & - & - & - & - & - & - & - & - & 1 \\
\hline 61 & $\begin{array}{l}\text { Mamestra bras- } \\
\text { sicae (Linnaeus, } \\
1758)\end{array}$ & 15 & 12 & 3 & 1 & 1 & - & 10 & 4 & 6 & - & - & - & - & - & - & 26 \\
\hline 62 & $\begin{array}{l}\text { Melanchra persi- } \\
\text { cariae (Linnaeus, } \\
1761 \text { ) }\end{array}$ & - & - & - & - & - & - & - & - & - & 1 & - & 1 & - & - & - & 1 \\
\hline 63 & $\begin{array}{l}\text { Sideridis rivu- } \\
\text { laris (Fabricius, } \\
1775 \text { ) }\end{array}$ & - & - & - & 1 & 1 & - & 1 & 1 & - & - & - & - & - & - & - & 2 \\
\hline 64 & $\begin{array}{l}\text { S. reticulata (Goe- } \\
\text { ze, 1781) }\end{array}$ & 14 & 11 & 3 & 3 & 2 & 1 & 17 & 11 & 6 & 23 & 7 & 16 & 1 & - & 1 & 58 \\
\hline 65 & $\begin{array}{l}\text { S. turbida (Esper, } \\
1790 \text { ) }\end{array}$ & - & - & - & 1 & - & 1 & - & - & - & 3 & 3 & - & 4 & 3 & 1 & 8 \\
\hline 66 & $\begin{array}{l}\text { Leucania obsoleta } \\
\text { (Hübner, 1803) }\end{array}$ & 2 & 2 & - & - & - & - & - & - & - & - & - & - & - & - & - & 2 \\
\hline 67 & $\begin{array}{l}\text { Mythimna albi- } \\
\text { puncta (Denis \& } \\
\text { Schiffermüller, } \\
1775 \text { ) } \\
\end{array}$ & 12 & 6 & 6 & 16 & 7 & 9 & 9 & 2 & 7 & 12 & 7 & 5 & 48 & 28 & 20 & 97 \\
\hline 68 & $\begin{array}{l}\text { M. ferrago (Fabri- } \\
\text { cius, 1787) }\end{array}$ & 4 & 2 & 2 & 5 & 3 & 2 & 6 & 2 & 4 & 5 & 1 & 4 & 6 & 5 & 1 & 26 \\
\hline 69 & $\begin{array}{l}\text { M. I-album (Lin- } \\
\text { naeus, 1767) }\end{array}$ & 17 & 15 & 2 & 5 & 4 & 1 & 2 & 2 & - & 5 & 4 & 1 & 14 & 8 & 6 & 43 \\
\hline 70 & $\begin{array}{l}\text { M. pallens (Lin- } \\
\text { naeus, 1758) }\end{array}$ & - & - & - & 2 & 2 & - & - & - & - & - & - & - & - & - & - & 2 \\
\hline 71 & $\begin{array}{l}\text { M. turca (Lin- } \\
\text { naeus, 1761) }\end{array}$ & - & - & - & 1 & - & 1 & 6 & 2 & 4 & - & - & - & - & - & - & 7 \\
\hline 72 & $\begin{array}{l}\text { M. vitellina (Hüb- } \\
\text { ner, 1808) }\end{array}$ & - & - & - & 1 & 1 & - & 4 & 2 & 2 & 12 & 10 & 2 & 4 & 3 & 1 & 21 \\
\hline 73 & \begin{tabular}{|l|} 
Agrotis bigramma \\
(Esper, 1790)
\end{tabular} & - & - & - & 1 & - & 1 & - & - & - & 1 & - & 1 & - & - & - & 2 \\
\hline 74 & $\begin{array}{l}\text { A. cinerea (Denis } \\
\& \text { Schiffermüller, } \\
1775 \text { ) }\end{array}$ & - & - & - & & - & - & - & - & - & 2 & 2 & - & - & - & - & 2 \\
\hline 75 & $\frac{\text { A. exclamationis }}{\text { (Linnaeus, 1758) }}$ & 75 & 54 & 21 & 83 & 55 & 28 & 74 & 53 & 21 & 100 & 54 & 46 & 134 & 84 & 50 & 466 \\
\hline 76 & $\begin{array}{l}\text { A. ipsilon (Hufna- } \\
\text { gel, 1766) }\end{array}$ & 3 & 2 & 1 & 1 & 1 & - & - & - & - & 5 & - & 5 & - & - & - & 9 \\
\hline
\end{tabular}




\begin{tabular}{|c|c|c|c|c|c|c|c|c|c|c|c|c|c|c|c|c|c|}
\hline 77 & $\begin{array}{l}\text { A. segetum (Denis } \\
\text { \& Schiffermüller, } \\
1775 \text { ) }\end{array}$ & 12 & 10 & 2 & 2 & 1 & 1 & 24 & 21 & 3 & 88 & 53 & 35 & 5 & 4 & 1 & 131 \\
\hline 78 & $\begin{array}{l}\text { Dichagyris for- } \\
\text { cipula (Denis \& } \\
\text { Schiffermüller, } \\
1775 \text { ) }\end{array}$ & - & - & - & 7 & 4 & 3 & 5 & 5 & - & 2 & - & 2 & 9 & 5 & 4 & 23 \\
\hline 79 & $\begin{array}{l}\text { D. signifera (Denis } \\
\text { \& Schiffermüller } \\
\text { 1775) }\end{array}$ & - & - & - & 1 & - & 1 & 1 & 1 & - & - & - & - & 1 & - & 1 & 1 \\
\hline 80 & \begin{tabular}{|l|} 
Euxoa nigricans \\
(Linnaeus, 1761) \\
\end{tabular} & - & - & - & - & - & - & - & - & - & - & - & - & 8 & 4 & 4 & 8 \\
\hline 81 & $\begin{array}{l}\text { E. obelisca (Denis } \\
\& \text { Schiffermüller, } \\
1775)\end{array}$ & - & - & - & - & - & - & - & - & - & - & - & - & 6 & 3 & 3 & 6 \\
\hline 82 & $\begin{array}{l}\text { *E. temera (Hüb- } \\
\text { ner, 1808) }\end{array}$ & - & - & - & - & - & - & - & - & - & - & - & & 3 & 1 & 2 & 3 \\
\hline 83 & $\begin{array}{l}\text { E. tritici (Linnaeus, } \\
1761 \text { ) }\end{array}$ & 2 & 2 & - & - & - & - & - & - & - & - & - & - & 1 & 1 & - & 3 \\
\hline 84 & $\begin{array}{l}\text { Axylia putris (Lin- } \\
\text { naeus, 1761) }\end{array}$ & 11 & 4 & 7 & 18 & 12 & 6 & 67 & 42 & 25 & 7 & 6 & 1 & 17 & 12 & 5 & 120 \\
\hline 85 & $\begin{array}{l}\text { *Chersotis marga- } \\
\text { ritacea } \\
\text { (Villers, 1789) }\end{array}$ & 3 & 2 & 1 & 4 & 3 & 1 & 5 & 5 & - & 1 & 1 & - & 1 & 1 & - & 14 \\
\hline 86 & $\begin{array}{l}{ }^{\star C} \text {. rectangu- } \\
\text { la (Denis \& Schi- } \\
\text { ffermüller, 1775) }\end{array}$ & 1 & 1 & - & 1 & 1 & - & 1 & 1 & - & - & - & - & 3 & 2 & 1 & 6 \\
\hline 87 & $\begin{array}{l}\text { Eugnorisma de- } \\
\text { puncta (Linnaeus, } \\
1761 \text { ) }\end{array}$ & 1 & 1 & - & - & - & - & - & - & - & - & - & - & - & - & - & 1 \\
\hline 88 & $\begin{array}{l}\text { Noctua fimbriata } \\
\text { (Schreber, 1759) }\end{array}$ & - & - & - & - & - & - & 2 & 2 & - & 1 & 1 & - & 14 & 14 & - & 17 \\
\hline 89 & $\begin{array}{l}\text { N. interposita } \\
\text { (Hübner, 1790) }\end{array}$ & - & - & - & - & - & - & 2 & 1 & 1 & - & - & - & 15 & 9 & 6 & 17 \\
\hline 90 & $\begin{array}{l}\text { N. janthina (Denis } \\
\text { \& Schiffermüller, } \\
1775)\end{array}$ & - & - & - & - & - & - & 1 & - & 1 & 1 & 1 & - & 9 & 5 & 4 & 11 \\
\hline 91 & $\begin{array}{l}\text { N. orbona (Hufna- } \\
\text { gel, 1766) }\end{array}$ & - & - & - & - & - & - & - & - & - & - & - & - & 2 & 2 & - & 2 \\
\hline 92 & $\begin{array}{l}\text { N. pronuba (Lin- } \\
\text { naeus, 1758) }\end{array}$ & 1 & - & 1 & 2 & 2 & - & 28 & 26 & 2 & - & - & - & 3 & 2 & 1 & 34 \\
\hline 93 & $\begin{array}{l}\text { *N. tertia (Mentzer } \\
\& \text { al., 1991) } \\
\end{array}$ & - & - & - & - & - & - & 1 & 1 & - & - & - & - & - & - & - & 1 \\
\hline 94 & $\begin{array}{l}\text { Ochropleura } \\
\text { plecta (Linnaeus, } \\
1761 \text { ) }\end{array}$ & 5 & 4 & 1 & 6 & 5 & 1 & - & - & - & 2 & - & 2 & 3 & 2 & 1 & 16 \\
\hline 95 & $\begin{array}{l}\text { Spaelotis ravida } \\
\text { (Denis \& Schiffer- } \\
\text { müller, 1775) } \\
\end{array}$ & - & - & - & - & - & - & - & - & - & - & - & - & 1 & 1 & - & 1 \\
\hline 96 & $\begin{array}{l}\text { Xestia c-nigrum } \\
\text { (Linnaeus, 1758) }\end{array}$ & 23 & 20 & 3 & 20 & 11 & 9 & 189 & 140 & 49 & 19 & 17 & 2 & 48 & 31 & 17 & 299 \\
\hline 97 & $\begin{array}{l}\text { X. triangulum (Hu- } \\
\text { fnagel, 1766) }\end{array}$ & 1 & 1 & - & - & - & - & 3 & 2 & 1 & 1 & - & 1 & 1 & 1 & - & 6 \\
\hline 98 & $\begin{array}{l}\text { *X. sexstriga- } \\
\text { ta (Haworth, 1809) }\end{array}$ & - & - & - & - & - & - & - & - & - & - & - & - & 1 & 1 & - & 1 \\
\hline
\end{tabular}




\begin{tabular}{|c|c|c|c|c|c|c|c|c|c|c|c|c|c|c|c|c|c|}
\hline 99 & $\begin{array}{l}\text { X. xanthographa } \\
\text { (Denis \& Schiffer- } \\
\text { müller, 1775) } \\
\end{array}$ & - & - & - & - & - & - & - & - & - & 3 & 3 & 0 & 6 & 5 & 2 & 9 \\
\hline 100 & $\begin{array}{l}\text { O. incerta (Hufna- } \\
\text { gel, 1766) }\end{array}$ & 1 & - & 1 & - & - & - & - & - & - & - & - & - & - & - & - & 1 \\
\hline 101 & $\begin{array}{l}\text { Phlogophora me- } \\
\text { ticulosa (Linnaeus, } \\
1758 \text { ) }\end{array}$ & - & - & - & - & - & - & - & 1 & 1 & - & - & - & 3 & 3 & - & 4 \\
\hline 102 & $\begin{array}{l}\text { Spodoptera } \\
\text { exigua (Hübner, } \\
\text { 1808) }\end{array}$ & 2 & 1 & 1 & - & - & - & - & - & - & - & - & - & - & - & - & 2 \\
\hline 103 & $\begin{array}{l}\text { Tholera cespitis } \\
\text { (Denis \& Schiffer- } \\
\text { müller, 1775) }\end{array}$ & 1 & 1 & - & 1 & 1 & - & - & - & - & - & - & - & 1 & 1 & - & 3 \\
\hline 104 & $\begin{array}{l}\text { T. decimalis (Poda, } \\
\text { 1761) }\end{array}$ & 13 & 4 & 9 & 8 & 4 & 4 & 14 & 5 & 9 & - & - & - & 9 & 8 & 1 & 44 \\
\hline 105 & $\begin{array}{l}\text { Polymixis polymi- } \\
\text { ta (Linnaeus, } \\
1761 \text { ) }\end{array}$ & 1 & 1 & - & - & - & - & - & - & - & - & - & - & - & - & - & 1 \\
\hline 106 & $\begin{array}{l}\text { Atethmia cen- } \\
\text { trago (Haworth, } \\
\text { 1809) }\end{array}$ & 1 & 1 & - & 1 & 1 & - & 2 & - & 2 & 5 & 4 & 1 & 10 & 7 & 3 & 19 \\
\hline 107 & $\begin{array}{l}\text { Cosmia diffinis } \\
\text { (Linnaeus, 1767) }\end{array}$ & - & - & - & - & - & - & - & - & - & 1 & - & 1 & - & - & - & 1 \\
\hline 108 & $\begin{array}{l}\text { Agrochola litura } \\
\text { (Linnaeus, 1758) }\end{array}$ & 2 & 1 & 1 & - & - & - & - & - & - & 2 & 1 & 1 & 2 & - & 2 & 6 \\
\hline 109 & $\begin{array}{l}\text { A. laevis (Hübner, } \\
\text { 1803) }\end{array}$ & - & - & - & - & - & - & - & - & - & - & - & - & 1 & 1 & - & 1 \\
\hline 110 & $\begin{array}{l}\text { A. circellaris (Huf- } \\
\text { nagel, 1766) }\end{array}$ & - & - & - & 3 & 1 & 2 & - & - & - & - & - & - & 1 & 1 & - & 4 \\
\hline 111 & \begin{tabular}{|l|} 
*Atypha pulmo- \\
naris (Esper, 1790)
\end{tabular} & - & - & - & - & - & - & - & - & - & - & - & - & 2 & 1 & 1 & 2 \\
\hline 112 & $\begin{array}{l}\text { Conistra rubigino- } \\
\text { sa (Scopoli, 1763) }\end{array}$ & - & - & - & 1 & - & 1 & - & - & - & - & - & - & - & - & - & 1 \\
\hline 113 & $\begin{array}{l}\text { C. vaccinii (Lin- } \\
\text { naeus, 1761) }\end{array}$ & - & - & - & - & - & - & - & - & - & - & - & - & 1 & 1 & - & 1 \\
\hline 114 & $\begin{array}{l}\text { Eupsilia transversa } \\
\text { (Hufnagel, 1766) } \\
\end{array}$ & - & - & - & 1 & - & 1 & - & - & - & - & - & - & - & - & - & 1 \\
\hline 115 & $\begin{array}{l}\text { Lithophane orni- } \\
\text { topus } \\
\text { (Hufnagel, 1766) }\end{array}$ & - & - & - & 1 & - & 1 & - & - & - & - & - & - & - & - & - & 1 \\
\hline 116 & $\begin{array}{l}\text { Tiliacea sulphura- } \\
\text { go (Denis \& Schi- } \\
\text { ffermüller, 1775) }\end{array}$ & - & - & - & 1 & - & 1 & - & - & - & - & - & - & - & - & - & 1 \\
\hline 117 & $\begin{array}{l}\text { Xanthia icteritia } \\
\text { (Hufnagel, 1766) }\end{array}$ & - & - & - & 1 & 1 & - & - & - & - & - & - & - & - & - & - & 1 \\
\hline \multicolumn{18}{|c|}{ Subfamilia ONCOCNEMIDINAE } \\
\hline 118 & $\begin{array}{l}\text { Calophasia lu- } \\
\text { nula (Hufnagel, } \\
\underline{1766)}\end{array}$ & 1 & - & 1 & 1 & - & 1 & - & - & - & - & - & - & 1 & 1 & - & 3 \\
\hline \multicolumn{18}{|c|}{ Subfamilia PLUSIINAE } \\
\hline 119 & $\begin{array}{l}\text { Abrostola tri- } \\
\text { partita (Hufna- } \\
\text { gel, 1766) }\end{array}$ & - & - & - & - & - & - & - & - & - & 2 & - & 2 & 2 & - & 2 & 4 \\
\hline
\end{tabular}




\begin{tabular}{|l|l|l|l|l|l|l|l|l|l|l|l|l|l|l|l|l|l|}
\hline 120 & $\begin{array}{l}\text { A. asclepia- } \\
\text { dis (Denis \& } \\
\text { Schiffermüller, } \\
1775)\end{array}$ & - & - & - & - & - & - & 1 & - & 1 & - & - & - & - & - & - & 1 \\
\hline 121 & $\begin{array}{l}\text { Diachrysia chry- } \\
\frac{\text { sitis (Linnaeus, }}{1758)}\end{array}$ & - & - & 1 & 1 & - & 1 & - & 1 & 1 & - & 1 & 4 & 1 & 3 & 7 \\
\hline 122 & $\begin{array}{l}\text { D. stenochrysis } \\
\text { (Warren, 1913) }\end{array}$ & 2 & 1 & 1 & 3 & 1 & 2 & 7 & 3 & 4 & 2 & 1 & 1 & 13 & 10 & 3 & 27 \\
\hline 123 & $\begin{array}{l}\text { Macdunnou- } \\
\begin{array}{l}\text { ghia confusa } \\
\text { (Stephens, } \\
\text { 1850) }\end{array}\end{array}$ & 1 & - & 1 & 6 & 1 & 5 & 9 & 5 & 4 & 1 & - & 1 & - & - & - & 17 \\
\hline 124 & $\begin{array}{l}\text { Autographa } \\
\text { gamma (Lin- } \\
\text { naeus, 1758) }\end{array}$ & 5 & 4 & 1 & 11 & 7 & 4 & 5 & 3 & 2 & 1 & 1 & - & 9 & 7 & 2 & 31 \\
\hline
\end{tabular}

Notă: * - specie nouă pentru fauna Republicii Moldova, T - total exemplare, UV capcana cu lumină ultravioletă, A - capcana cu lumină albă.

\section{CONCLUZII}

În urma investigațiilor au fost colectate și determinate 3232 de exemplare de noctuide: la capcana cu lumină albă s-au colectat 1054 de exemplare, iar la cea ultravioletă - 2178 de exemplare.

S-au identificat 124 de specii, taxonomic încadrate în 71 de genuri și 11 subfamilii. Cele mai multe specii aparțin subfamiliei Noctuinae (95 specii), iar subfamiliile Metoponiinae și Oncocnemidinae înregistrează o singură specie.

Studiile au fost realizate în cadrul proiectului instituțional fundamental 15.817.02.12F.

\section{BIBLIOGRAFIE}

1. Fauna Europaea,Web Service // Fauna Europaea version 2.6.2., 2013 (available online at http://www.faunaeur.org).

2.Rakosy L. Fauna de macrolepidoptere de la Fâneţele Clujului (Lepidoptera). În: Bul. Inf. Soc. Lepid. Rom. 8 (3-4), 1997. p. 165-186.

3.Țugulea C. Specii noi de Noctuide (Lepidoptera, Noctuidae) în fauna Republicii Moldova // International symposium „Actual problems of zoology and parasitology: Achievements and prospects" 13 october 2017, Chișinău 2017: 347

4.T,ugulea C., Derjanschi V. Istoricul studiului noctuidelor (Lepidoptera, Noctuidae) în Republica Moldova // Buletin Științific. Revistă de Etnografie, Științele Naturii și Muzeologie. Nr. 22 (35). Serie nouă. Fascicula Științele Naturii. Chișinău, 2015: 59-81. 